\title{
Right ventricular failure after left ventricular assist device implantation: a review of the literature
}

\author{
Valeria Lo Coco ${ }^{1}$, Maria Elena De Piero ${ }^{1,2}$, Giulio Massimi ${ }^{1,3}$, Giovanni Chiarini ${ }^{1,4}$, Giuseppe M. Raffa ${ }^{5}$, \\ Mariusz Kowalewski ${ }^{1,6}$, Jos Maessen ${ }^{1,7}$, Roberto Lorusso ${ }^{1,7}$ \\ ${ }^{1}$ Cardio-Thoracic Surgery Department, Heart and Vascular Centre, Maastricht University Medical Centre, Maastricht, the Netherlands; \\ ${ }^{2}$ Department of Anesthesia/Intensive Care, San Giovanni, Turin, Italy; ${ }^{3}$ Department of Cardiac Surgery, Circolo Hospital, University of Insurbia, \\ Varese, Italy; ${ }^{4}$ Division of Anesthesiology, Intensive Care and Emergency medicine, Spedali Civili University, Brescia, Italy; ${ }^{5}$ Department for the \\ Treatment and Study of Cardiothoracic Diseases and Cardiothoracic Transplantation, IRCCS-ISMETT, Palermo, Italy; ${ }^{6}$ Thoracic Research Centre, \\ Collegium Medicum, Nicolaus Copernicus University, Innovative Medical Forum, Bydgoszcz, Poland; ${ }^{7}$ Cardiovascular Research Institute Maastricht \\ (CARIM), Maastricht, the Netherlands \\ Contributions: (I) Conception and design: R Lorusso; (II) Administrative support: V Lo Coco, J Maessen; (III) Provision of study materials or patients: \\ V Lo Coco, GM Raffa, M Kowalewski; (IV) Collection and assembly of data: V Lo Coco, ME De Piero; (V) Data analysis and interpretation: V Lo \\ Coco, G Massimi, G Chiarini; (VI) Manuscript writing: All authors; (VII) Final approval of manuscript: All authors. \\ Correspondence to: Dr. Valeria Lo Coco. Cardiothoracic Surgery Department, Heart \& Vascular Centre, Maastricht University Medical Centre \\ (MUMC), P. Debyelaan, 12-221 AZ Maastricht, The Netherlands. Email: valeria.lococo@hotmail.com.
}

\begin{abstract}
Right ventricular failure (RVF) following left ventricular assist device (LVAD) implantation remains a major complication which may significantly impair patient outcome. The genesis of RVF is, however, multifactorial, and the mechanisms underlying such a condition have not been fully elucidated, making its prevention challenging and the course not always predictable. Although preoperative risks factors can be associated with RV impairment, the physiologic changes after the LV support, can still hamper the function of the RV. Current medical treatment options are limited and sometimes, patients with a severe post-LVAD RVF may be unresponsive to pharmacological therapy and require more aggressive treatment, such as temporary RV support. We retrieved 11 publications which we assessed and divided in groups based on the RV support [extracorporeal membrane oxygenation (ECMO), right ventricular assist device (RVAD), TandemHeart with ProtekDuo cannula]. The current review comprehensively summarizes the main studies of the literature with particular attention to the RV physiology and its changes after the LVAD implantation, the predictors and prognostic score as well as the different modalities of temporary mechanical cardiocirculatory support, and its effects on patient prognosis for RVF in such a setting. In addition, it provides a decision making of the pre-, intra and post-operative management in high- and moderate- risk patients.
\end{abstract}

Keywords: Right ventricular failure (RVF); left ventricular assist device (LVAD); right ventricular assist device (RVAD); mechanical cardio-circulatory support; extracorporeal membrane oxygenation (ECMO)

Submitted Jun 17, 2020. Accepted for publication Nov 26, 2020.

doi: $10.21037 /$ jtd-20-2228

View this article at: http://dx.doi.org/10.21037/jtd-20-2228

\section{Introduction}

Right ventricular failure (RVF) following left ventricular assist device (LVAD) placement is a complex disease including many causes and pathological events (1). A right-sided failure may complicate $10 \%$ to $40 \%$ of LVAD implantations and is associated with prolonged length of intensive care unit and hospital stay, as well as high morbidity and mortality (2-4).

In case of refractory RVF, temporary mechanical cardiocirculatory supports may be required. New percutaneous devices, specifically designed for the RV, have been 
introduced into the clinical practice $(5,6)$. Although technology developments, the perfect timing of implant, the more appropriate configuration and device, as well as the identification of high-risk patients is not well clarified representing still a challenge. We present the following article in accordance with the PRISMA reporting checklist (available at http://dx.doi.org/10.21037/jtd-20-2228).

\section{Material and methods}

We systematically searched the main articles in the current literature through PubMed and MEDLINE database. Search terms included right ventricular failure-left ventricular assist device-right ventricular assist device-mechanical cardio-circulatory supportextracorporeal membrane oxygenation. Complete details, including electronic search strategy, objectives, criteria for study selection, eligibility, data collection, and assessment of study quality, were registered and published online in PROSPERO-International Prospective Register of Systematic Reviews (Registration Number: CRD42019134835).

The search was limited to human studies; no language restrictions were imposed. We made a screening of titles and abstracts identifying those records which considered patients with heart failure, treated with LVAD, and in which a proportion of the whole recruited population developed acute RVF (i.e., within 2 weeks of LVAD implantation). Furthermore, we verified that relevant data were available focusing on their quality and relevance assessment. We included studies with the following criteria: data were stratified for both RVF and No-RVF patients; data were expressed as $\mathrm{n}(\%)$ or mean \pm standard deviation and included clear denominators. Additional references were identified analyzing the bibliographies of the evaluated articles. The exclusion criteria were as follows: patients treated with medical therapy or intra-aortic balloon pump (IABP), biventricular assist device (BiVAD), neonatal/pediatric populations (i.e., 17 years old or younger) and case reports.

We retrieved 21 publications; after removal of nonpertinent reports, case reports, and studies in which the demography of the patients, the strategy and their outcome were not detailed, 12 papers remained. These studies were assessed and divided in four categories based on the strategy of right ventricle (RV) support:

* Isolated LVAD vs. LVAD-extracorporeal membrane oxygenation (ECMO);

* Isolated LVAD vs. LVAD-right ventricular assist

\section{device (RVAD); \\ * Isolated LVAD vs. LVAD-ECMO vs. LVAD- RVAD; \\ * LVAD-Tandemlife ProtekDuo.}

The PRISMA flow diagram, describing the decisionmaking process about the management of the RVF after LVAD, is presented in Figure 1.

\section{Changes in right ventricular function after LVAD placement}

The genesis of the RVF is multifactorial and pathological events can increase RV afterload, decrease RV preload, or impair the contractility (7). Indeed, preoperative existing RV dysfunction may be aggravated by further physiologic changes related to LVAD implant $(8,9)$. The increasing $\mathrm{LV}$ output could precipitate RVF through two mechanisms: volume overloading of the RV owing to an increased flow in the systemic circulation or a decrease in RV pump function caused by an interventricular septal (IVS) shift into the LV due to an exaggerated drainage (10). Thus, emptying the LV by exaggerated LVAD pump flow could interfere with RV function by compromising the contribution of the IVS to RV contraction due to the two ventricles interdependence (10). On the other hand, the reduction in LV congestion obtained by appropriate draining, may relieve the RV by reducing RV afterload, increasing the aortic and thus coronary blood flow, reversing a septal shift into the RV from a distended LV (11). The acute unloading of the LV, the increase of right-sided preload and the cardiac output leads to a septal shift thereby alter RV shape and size with modifications in the RV contractility. In addition, in the setting of an incompetent tricuspid valve, the increased $\mathrm{RV}$ volume and the left-ward shift of the septum may cause a tethering of valve leaflets, further deteriorating or generating hemodynamically critical tricuspid regurgitation $(11,12)$. Among other reasons, an increased RV afterload due to pulmonary vasoconstriction and tachyarrhythmia which can double the risk of RVF have been also proposed $(13,14)$.

Although the above-mentioned reasons are the most common explanations, the full understanding of the pathophysiology of LVAD-related RVF remains still not well understood.

\section{Prognostic score and risk factors for RVF}

In the last years, a growing interest has been observed about 
PRISMA 2009 Flow Diagram
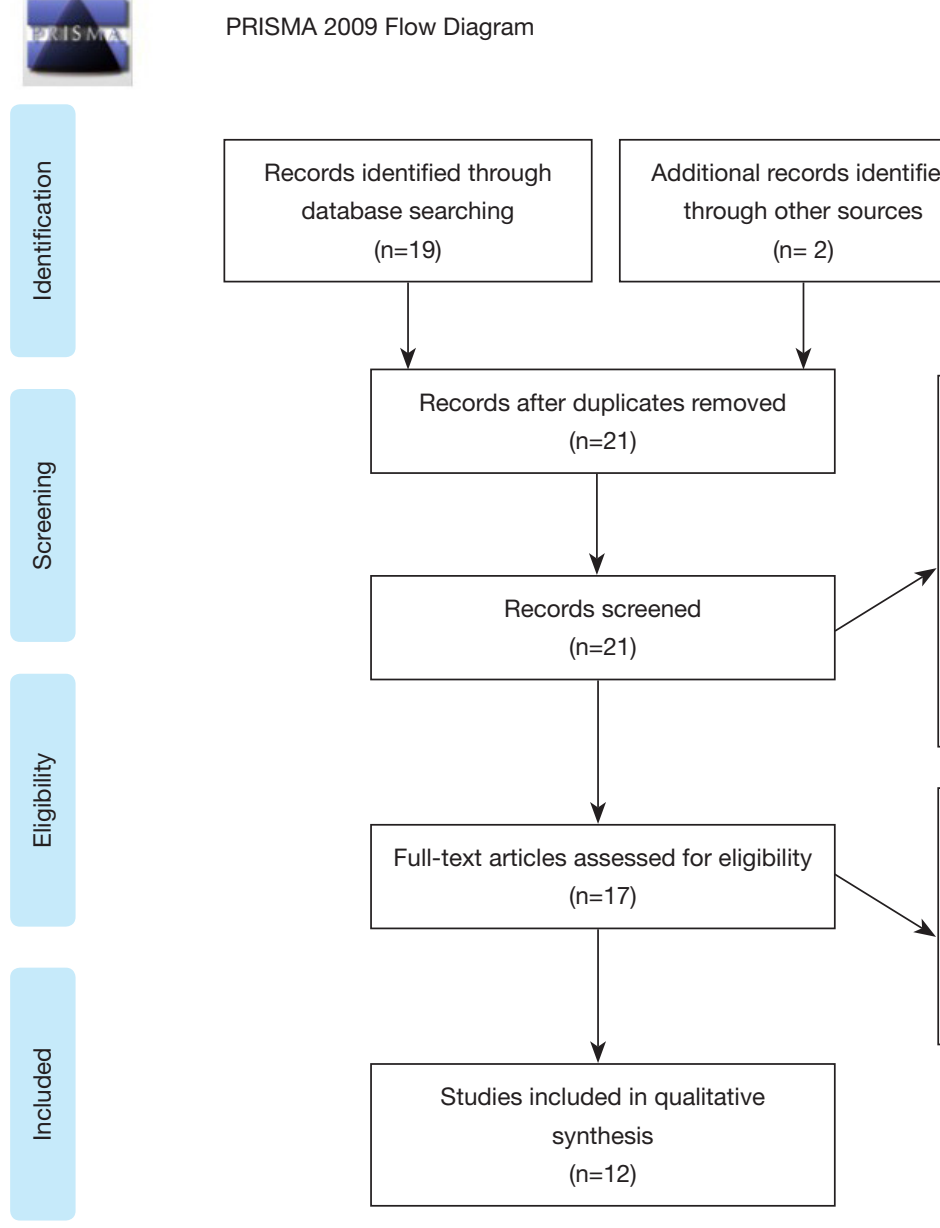

Records excluded $(n=4)$

Reasons:

- Patients treated with only medical therapy or intraortic balloon pump

- Biventricular assist device

- Neonatal/pediatric populations (i.e.

17 years old or younger)

- Case reports, irrelevant review, letter, brief communication

Full-text articles excluded, $(n=5)$

Reasons:

Not possible to assess demography of the populations, not clearly specified the mechanical cardio-circulatory support used, outcome data not recorded.

Figure 1 Prisma flow diagram.

realizing risk models to predict RVF occurrence post-LVAD. Identifying patients at high risk for such a complication has been associated with improved management and outcomes $(15,16)$ (Figure 2). Recent studies have highlighted a few predictors for such an adverse event: female gender, preoperative circulatory support, prior cardiac surgery and non-ischemic etiology of heart failure have all been found prognostic of RVF in this setting (17-19). The HeartMate II risk model reported CVP/pulmonary capillary wedge pressure $>0.63$, pre-operative mechanical ventilator support and blood urea nitrogen $>39 \mathrm{mg} / \mathrm{dL}$ as independent risk factors (20). Other important predictors for RVF are the pre-LVAD implant grade of tricuspid incompetence, the geometry of the RV (right ventricle end diastolic diameter $>35 \mathrm{~mm}$, RV ejection fraction $<30 \%$ and right atrial dimension $>50 \mathrm{~mm}$ ) in relation to pulmonary vascular resistance, elevated CVP, and evidence of liver and renal impairments (21).

After LVAD implant, a moderate-severe mitral regurgitation might also be predictive of the onset or deterioration of RVF. Regarding intervention on mitral valve regurgitation as protective intervention to prevent RVF occurrence, there is no agreement about the appropriate management (11). Indeed, the disappearance or improvement of mitral valve insufficiency, after the LVADrelated LV unloading, has been reported (22). In contrast, other studies have advocated the need of mitral repair as required and protective factor for early or late RVF occurrence $(23,24)$. This aspect, therefore, remains still controversial. Regarding tricuspid valve anomalies (annulus $>40 \mathrm{~mm}$, moderate or severe regurgitation), tricuspid valve repair concomitant LVAD implant has also been advocated $(25,26)$.

The risk for post-LVAD RVF has been associated at 


\begin{tabular}{|l|}
\hline \multicolumn{1}{|c|}{ Moderate Risk RVF } \\
Female gender \\
Non-ischemic etiology of heart failure \\
Vasopressor use \\
Echo parameters \\
TAPSE $\leq 16 \mathrm{~mm}$ \\
Pulsed-wave Doppler velocity at the \\
annulus $\leq 10 \mathrm{~cm} / \mathrm{s}$ \\
Fractional area change $35-20 \%$ \\
RVEED-to-LVEDD ratio $0.74 \pm 0.17$ \\
RVEDD $>35 \mathrm{~mm}$ \\
RV EF $<45 \%$ \\
Moderate TR \\
Moderate and/or severe $\mathrm{MR}$ \\
Hemodynamic parameters \\
Cl $\leq 2.2$ L/min \\
CVP $12-16 \mathrm{mmHg}$ \\
PVR $>2.8-4.2$ Wood unit \\
PA pulsatily index $<1.85$ \\
RVSWI $0.25-0.30 \mathrm{mmHg} / \mathrm{l} / \mathrm{m}^{2}$ \\
Organs parameters \\
BUN $>39 \mathrm{mg} / \mathrm{dl}$ \\
AST $\geq 80$ UI/L \\
\end{tabular}

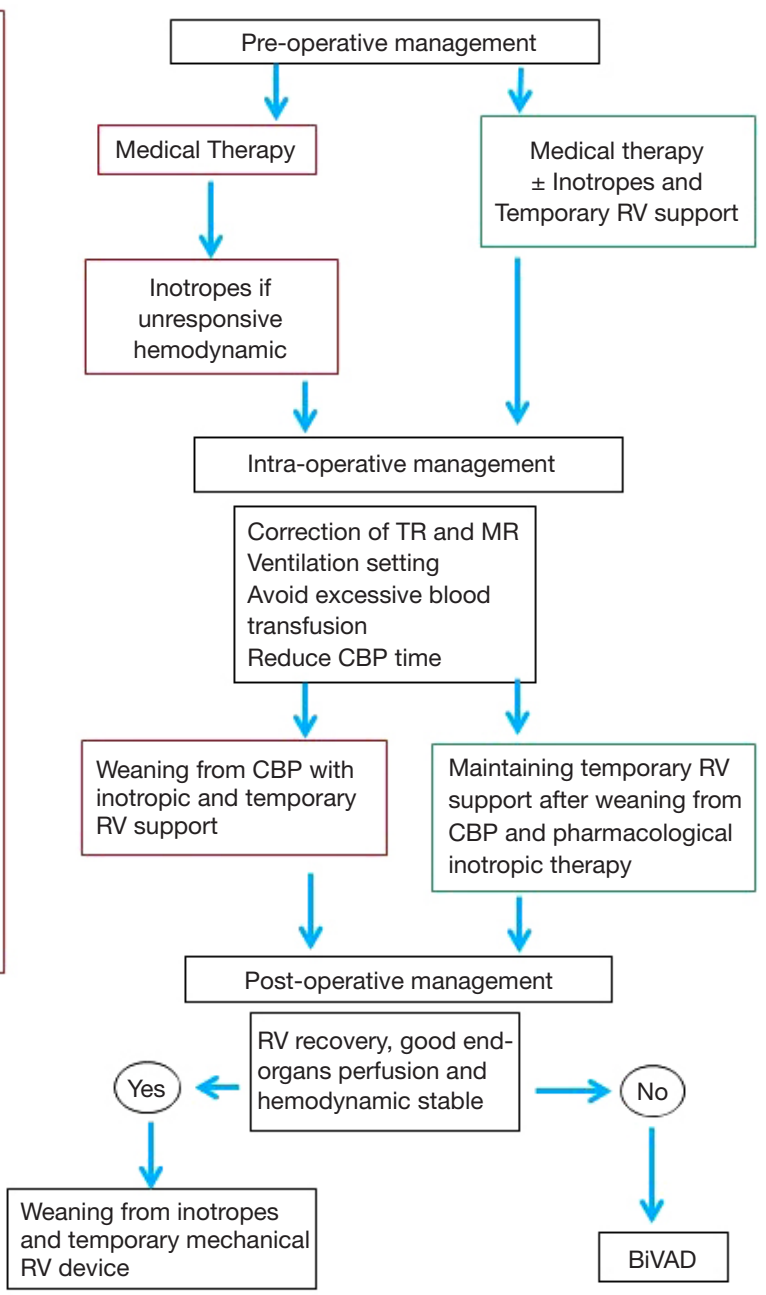

\begin{tabular}{|c|}
\hline High Risk RVF \\
\hline Preoperative circulatory support \\
\hline Prior cardiac surgery \\
\hline Pre-operative mechanical ventilator support \\
\hline Inotrope dependency \\
\hline Echo parameters \\
\hline TAPSE $<7.5 \mathrm{~mm}$ \\
\hline Pulsed-wave Doppler velocity at the annulus \\
\hline$<8 \mathrm{~cm} / \mathrm{s}$ \\
\hline FAC $<20 \%$ \\
\hline RVEED-to-LVEDD ratio $>0.75$ \\
\hline Sever TR, velocity $>2.5 \mathrm{~m} / \mathrm{s}$ \\
\hline Annulus tricuspid valve $>40 \mathrm{~mm}$ \\
\hline RVEDD $>40 \mathrm{~mm}$ \\
\hline RVESV $>44 \mathrm{~mL} / \mathrm{m}^{2}$ \\
\hline RV EF $<30 \%$ \\
\hline RA dimension $>50 \mathrm{~mm}$ \\
\hline $\begin{array}{l}\text { Dilated inferior vena cava with no inspiratory } \\
\text { variation on echocardiography }\end{array}$ \\
\hline Elevated jugular venous pressure \\
\hline Hemodynamic parameters \\
\hline CVP $>16 \mathrm{mmHg}$ \\
\hline $\mathrm{Cl}<2 \mathrm{l} / \mathrm{min}$ \\
\hline CVP/PCWP >0.63 \\
\hline $\mathrm{RVSWI} \leq 0.25 \mathrm{mmHg} / \mathrm{l} / \mathrm{m}^{2}$ \\
\hline PA pulsatily index $<1.85$ \\
\hline PVR $>4.3$ Wood unit \\
\hline $\mathrm{DPG}>7 \mathrm{mmHg}$ \\
\hline TPG $>12 \mathrm{mmHg}$ \\
\hline Organs parameters \\
\hline Creatinine $>2 \mathrm{mg} / \mathrm{dl}$ and/or Urine Output \\
\hline$<0.5 \mathrm{ml} / \mathrm{kg} / \mathrm{h}$ \\
\hline Bilirubine $>2 \mathrm{mg} / \mathrm{dl}$ \\
\hline Ascites or hepatomegaly \\
\hline Peripheral edema \\
\hline
\end{tabular}

Figure 2 Definition of moderate and high-risk patients for right ventricular failure after left ventricular assist device and their management in the pre-, intra- and post-operative. AST, aspartate aminotransferase; BiVAD, biventricular assist device; BUN, blood urea nitrogen; CI, cardiac index; CPB, cardio-pulmonary bypass; CVP, central venous pressure; DPG, diastolic pulmonary gradient; FAC, fractional area change; LVEDD, left ventricle end-diastolic diameter; MR, mitral regurgitation; PA, pulmonary artery; PVR, peripheral vascular resistance; RA, right atrium; RV, right ventricle; RVEDD, RV end-diastolic diameter; RV EF, RV ejection fraction; RVESV, RV end-systolic volume; RVF, RV failure; RVSWI, RV stroke work index; TAPSE, tricuspid annular plane systolic excursion; TR, tricuspid regurgitation.

other parameters. In the study by Atluri and colleagues (27), a preoperative high CVP was associated with a higher risk of RFV. Furthermore, Fukamachi et al. (28), demonstrated low RV stroke-work index and low pulmonary artery (PA) pressure to be significant predictors of RVF. Other studies identified low cardiac index, diastolic pulmonary gradient, elevated pulmonary vascular resistance as important risk factors (29-31).

As far as risk models for RVF are concerned, the Michigan RVF risk score and the CRITT score have been shown to be helpful about predicting the probability of developing LVAD-related RVF $(27,32)$. The Michigan score considers four variables: vasopressor use (assigning 4 points), creatinine $>2.3 \mathrm{mg} / \mathrm{dL}$ ( 3 points), bilirubin $>2 \mathrm{mg} / \mathrm{dL}$ (2.5 points) and aspartate aminotransferase $>80 \mathrm{IU} / \mathrm{dL}$ (2 points); a greater risk for RVF is associated with a higher score (32). Instead, the CRITT score is a risk score based on 5 clinical variables and 0 or 1 point is allotted for each of them, including CVP >15 mmHg, severe RV dysfunction, preoperative mechanical ventilation/intubation, severe 
tricuspid regurgitation, and tachycardia. A CRITT score less than 2 is highly predictive of the ability to tolerate isolated LVAD therapy (negative predictive value of 93\%) (26). Recently, Loforte and collaborators developed the ALMA score model (33). The parameters considered for the ALMA risk score include destination therapy, PA pulsatility index $<2$, right to left ventricular end-diastolic diameter ratio $>0.75, \mathrm{RV}$ stroke work index $<300 \mathrm{mmHg} / \mathrm{mL} / \mathrm{m}^{2}$, model for end-stage liver disease excluding international normalized ratio (MELD-XI) $>17$. In this risk model, an isolated LVAD is recommended for score of 0 or 1 , a BiVAD for patients with score of 4 or 5 , whereas a score of 2 represents a grey zone and they can benefit from an LVAD with an appropriate pharmacologic and/or a temporary RVAD (33). Besides these risk factors, unfortunately, the pre-operative risk assessment cannot account for intraoperative events such as air embolism, blood transfusion etc., which may influence the hemodynamic status and consequently, the RV function.

\section{Temporary right ventricular support}

Despite the optimal medical treatment, $4-6 \%$ of the patients with RVF after LVAD implantation are unresponsive to pharmacological therapy and requires a temporary ventricular support $(2,7)$. Several strategies have been described to support the RVF after LVAD implant. The RVF-device options include veno-arterial (V-A) ECMO, temporary RVAD (with/without oxygenator) with single lumen (Biomedicus or TandemLife) or double-lumen cannula (ProtekDuo® TandemLife), percutaneous devices (Impella RP® Abiomed), and, TandemHeart (TH-RVAD) (Figure 3) (Table 1).

One conventional approach includes peripheral V-A ECMO. It reduces LVAD preload due to RV unloading and increases the LVAD afterload with risk of reduced forward blood flow. With peripheral approach, the removal of the ECMO-related cannulas does not require a resternotomy and it costs less than any other mechanical support device. Common complications are bleeding, infections, and vascular complications (34). Regarding the reduced pre-load and increased afterload of the LVAD in the presence of peripheral V-A ECMO, such conditions translate into decreasing pump preload and increased pump afterload which might negatively influence the LVAD function. Therefore, in such a condition, it is important to accommodate the ECMO /LVAD interaction to avoid the competition between the two devices and the differential hypoxia phenomenon (35-37).

Another possible option implies the cannulation of the PA which may be approached with a surgical access in case of intraoperative, open-chest implant, or percutaneously via the right internal jugular vein (38). The surgical approach may be performed through a direct cannulation or via a prosthetic graft anastomosed to the main PA ("Chimney technique"). The direct PA cannulation requires open chest cannulation of the PA with cannulation of the RA with direct access or via the femoral vein, and it ensures complete unloading of the RV with an anterograde trans-pulmonary blood flow and an adequate preload for the LVAD. The associated limitations are the general anesthesia, mechanical ventilation and the necessity of re-sternotomy to withdraw the PA cannula, and, in case, also the RA cannula, which can increase bleeding and infection complications (39). Instead, the end-graft facilitated technique represents a simplified ECMO in which the venous inflow cannula is placed percutaneously into the RA through the femoral vein and the outflow cannula, through an $8 \mathrm{~mm}$ Dacron graft is anastomosed end-to-side to the main PA using a side clamp. The Dacron prosthesis is in front of the LVAD outflow graft and is tunneled to its percutaneous exit side at the subxiphoid level. The outflow cannula is then inserted into the Dacron graft and secured firmly to the chest wall using multiple sutures. Thus, it allows a bedside removal without a re-sternotomy. In literature, no vascular graft related problems (after months the graft appeared completely thrombosed without pseudo aneurysm, perigraft fluid collections, pulmonary embolism or bleeding) were observed. It is associated with good LVAD pre- and post-load and with less thromboembolic events than the peripheral V-A ECMO $(40,41)$.

Nowadays, new tools which can allow entirely percutaneous procedures have been developed. Indeed, the drainage cannula can be introduced from the femoral vein into the RA and a flexible outflow cannula can be place into the PA via the right internal jugular vein (42). An alternative fully percutaneous approach may be achieved with a single, double-lumen cannula, the PA is named ProtekDuo (TandemLife, Livanova, UK). This cannula is inserted in the right internal jugular vein to reach the main PA under fluoroscopy guidance, and allows $4 \mathrm{~L} / \mathrm{min}$ flow (43); one lumen works as inflow draining the blood from the RA, while the second lumen delivers the blood into the main PA thanks to a multi-fenestrated distal tip. Such a configuration includes an oxygenator in the circuit (realizing a so called "OxyRVAD" configuration). When there 


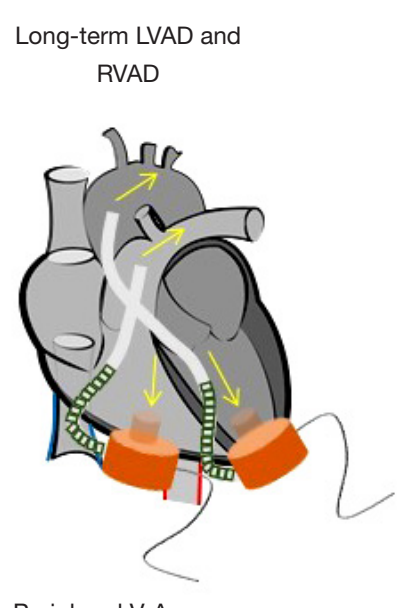

Peripheral V-A

ECMO and LVAD

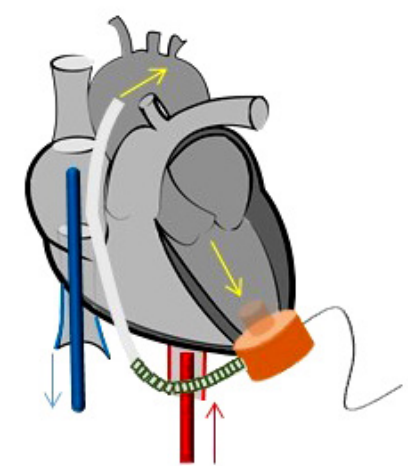

OxyRVAD with Biomedicus and LVAD

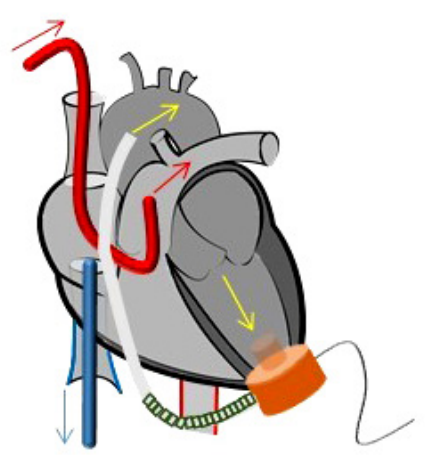

TH RVAD

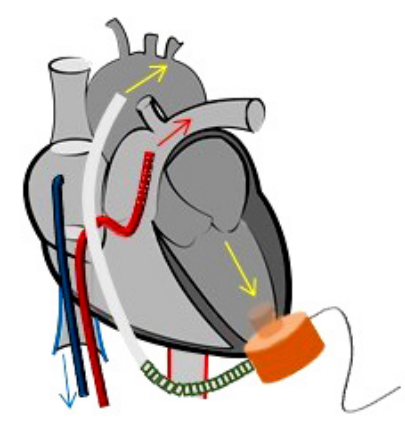

OxyRVAD with ProtekDuo and LVAD

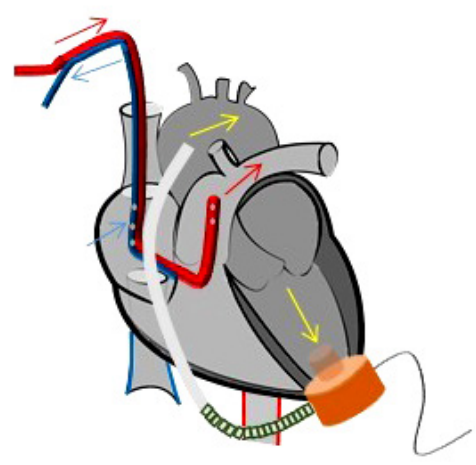

Impella RP

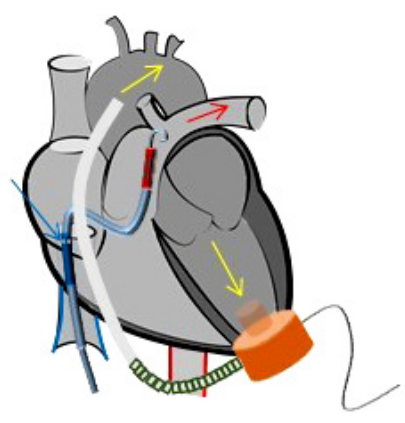

Figure 3 Temporary and long-term mechanical assist device for right ventricular failure after left ventricular assist device. LVAD, left ventricular assist device; OxyRVAD, right ventricular assist device with oxygenator; TH RVAD, TandemHeart RVAD; V-A ECMO, venoarterial extracorporeal membrane oxygenation.

is no impairment of the gas exchange, the oxygenator can be removed/avoided and a pure RVAD is obtained, enabling a prolonged support without anticoagulation, and avoiding the oxygenator-related complications (plasma leakage, systemic inflammation, coagulopathy and thrombo-embolism) (44-46). In addition, the groin-free strategy of support may allow patient awakening and mobilization, reducing thereby possible respiratory or vascular complications (44-46).

Another percutaneous option is the Impella RP (Abiomed, Denver) which is characterized by a microaxial flow catheter with a flow of $4-5 \mathrm{~L} / \mathrm{min}$. The catheter is placed into the right femoral vein and it ejects blood from the inferior vena cava into the PA, thereby bypassing the RV $(47,48)$. This device may, therefore, represents an additional fully percutaneous approach, but consistent series and evidences are still not available (49).

The TH RVAD constitutes an additional percutaneous option for RVF. It delivers the blood through 2 venous cannulas. The inflow cannula is placed in RA via the left femoral vein, instead, the outflow cannula in PA through the right femoral vein. Another site of cannulation for the outflow is the right internal jugular vein, it can be used in case the femoral venous access is prohibitive: thrombosis, infection or inferior cava filters or in case of tall patients (distance from the femoral vein to the fifth intercostal space exceeds $58 \mathrm{~cm})(50)$.

Another possible strategy, mostly in case of patient with an LVAD bridge-to-transplantation, is represented by a right VAD. In this respect, there are only small series and case reports available. The weaning rate from the right VAD was possible in the $45-75 \%$ of the patients (51). The major complication was represented bleeding and thrombosis of the VAD (52). They include the LVAD (Jarvik and HeartWare devices) (53) used in right position and the CentriMag paracorporeal VAD $(54,55)$. For several reasons, such an approach is currently less considered for the related 


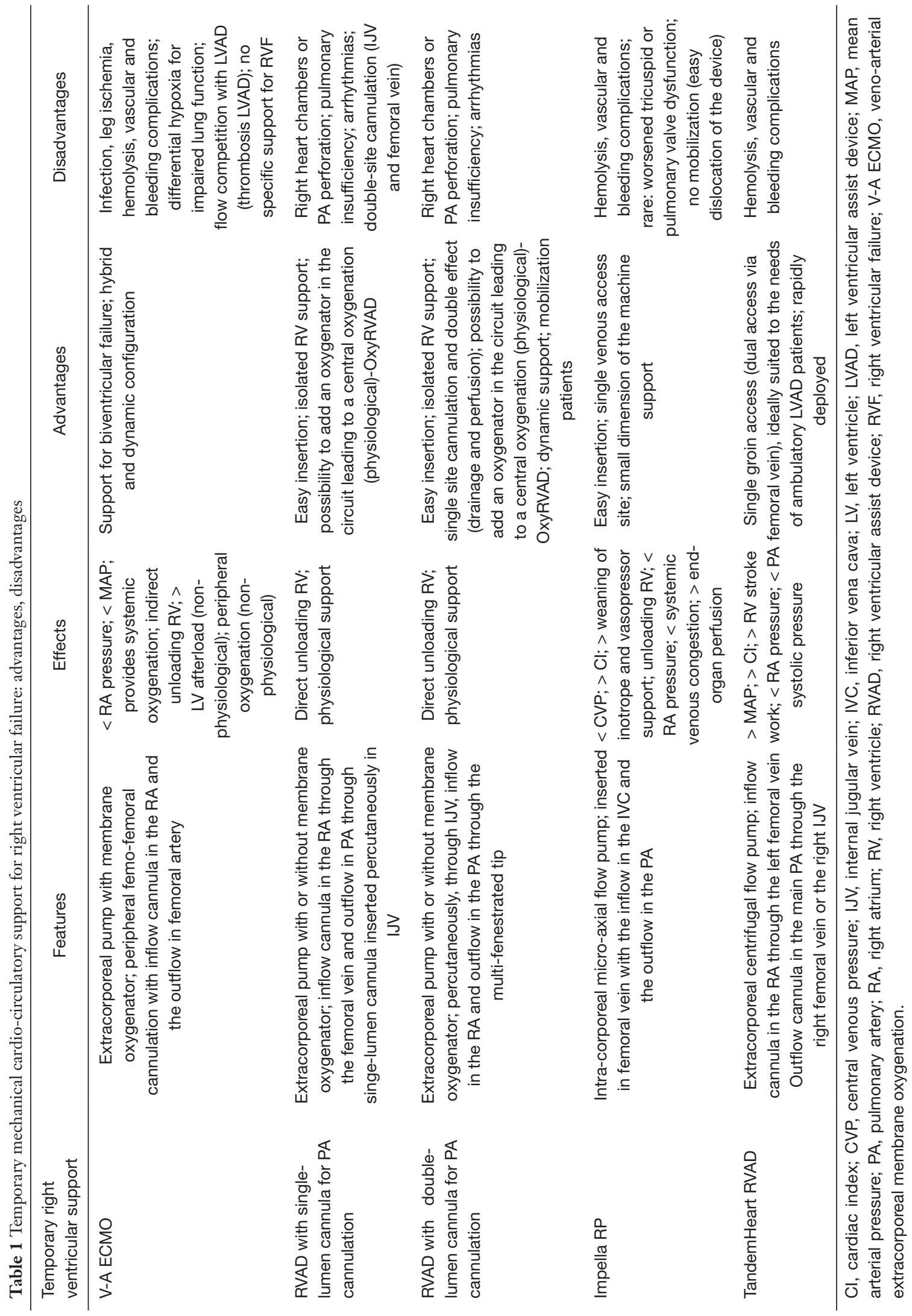


cost and invasiveness.

\section{Discussion}

Acute RVF is still a common complication after LVAD implantation associated with a reduced efficacy of LVAD in terms of flow and organ perfusion and a 6-month mortality reaching up to $29 \%$. Its pathophysiology and management are complex and remain controversial (56-58). Despite optimized medical therapy, a significant number of LVAD patients still need a perioperative mechanical RV support. The outcome is different depending on the type of right assist device and the patient characteristics (Table 2). Kormos and collaborators (20), showed that patients receiving the HeartMate II with early RVF had a $20 \%$ reduction in 1-year survival compared with patients who did not have RVF. In the EUROMACS Registry, Soliman and colleagues described 2988 patients who had a LVAD, and the cumulative survival in the postoperative 24 months was higher in patients without RVF at the 6-month $(79 \%$ versus $61 \%), 12$-month (71\% versus $53 \%), 18$-month $(65 \%$ versus $49 \%$ ), and 24 -month (58\% versus $45 \%$ ) follow-up, compared with patients with RVF (66).

Another factor which influences the prognosis in such a setting is the timing of RV support. Sometimes the severity of RVF is underestimated prior to or at the LVAD implant, with delayed RV support and consequent worse outcome. Bhama and associates, showed a better overall survival at 3 months in patients who received an immediate RVAD as compared to a delayed support (79\% vs. 46\%) (63). Additionally, a recent study reported that the early use of a temporary RVAD in case of risk factors of RVF could improve the outcome and consequently decrease the overall mortality (62).

The duration of the support seems to affect the outcomes as well. In particular, a RV support lasting for more than 7 days and a blood flow greater than 4L/min after LVAD may be associated with pulmonary bleeding complications due to the non-pulsatile flow perfusion of the lung during RVAD (67). Other studies confirmed the importance of the temporary ECMO for the right support (68). In particular, Riebandt and associates (61), showed that patients treated with ECMO have a $75 \%$ of in-hospital survival with no post-discharge mortality at 1 year. Another relevant experience was reported by Scherer and colleagues (60), who suggested that a preoperative ECMO can stabilize organ perfusion before the LVAD implantation and, in order to avoid RVF, it should not be removed for the immediate postoperative period. Furthermore, Leidenfrost and collaborators (64), reported improved metabolic parameters and a lower 30-day mortality in patients who received a RVAD after continuous-flow LVAD implantation.

In case of biventricular failure, it's still not clear which is the perfect strategy of management. Shehab and colleagues (59), compared the outcome of BIVAD and a veno-pulmonary arterial ECMO, and observed that the ECMO is associated with a better in-hospital and late survival. A long-term dual VAD could be considered in patients with evident RVF. Those with mild signs of RVF may benefit from temporary percutaneous implantable pumps in the early perioperative period to allow for RV hemodynamic stabilization (69). A recent study showed another viable option in case of biventricular failure through the combination of an Impella CP, inserted via the axillary artery, with the ProtekDuo, connected with a TH pump allowing the patient to be awake during the support and the mobilization (70). Since its introduction in 2016, ProtekDuo cannula has been used mostly for RVF after LVAD. It provides good outcome with a high rate of weaning and RV recovery from the support. Clinical trials have to be conducted to elucidate the timing and the exact patient population $(71,72)$. The largest experience with ProtekDuo has been reported by Ravichandran and collaborators (65). They showed how an earlier placement of the double-lumen cannula improves outcomes and reduces common complications (65).

Another percutaneous device for the RVF is the Impella RP. Hemodynamically, Impella has shown to increase the cardiac index restoring the forward perfusion, decrease the CVP, unloading of the RV, reducing systemic venous congestion and enhancing the end-organ perfusion. Its placement in LVAD patients with post-operative RVF has been associated with less necessity of inotropic or vasopressor therapy and a better outcome (survival at 30 -days or discharge in $83 \%$; all discharged patients were alive at 180 days) (48). There were no thromboembolic complications, no pulmonary embolism, and minimal cardiac structure or vascular perforation or damage. The most prevalent complication was bleeding, however, with a lower rate compared to surgical RVAD and hemolysis, while worsening of tricuspid or pulmonary valve dysfunction was infrequent. The access site to the femoral vein is however, limiting patient mobilization $(47,73,74)$. The use of Impella is growing in the context of isolated RVF and biventricular dysfunction in patients with short- and long-term LVAD. For the biventricular support, the BIPELLA, a combination 
Table 2 Comparison outcome of different right mechanical supports for right ventricular failure after left ventricular assist device

\begin{tabular}{|c|c|}
\hline Study & Patients features \\
\hline \multicolumn{2}{|c|}{$\begin{array}{l}\text { Isolated LVAD vs. } \\
\text { LVAD-ECMO }\end{array}$} \\
\hline $\begin{array}{l}\text { Shehab } \\
\text { et al. (59) }\end{array}$ & $\begin{array}{l}75 \text { isolated LVAD-mean age: 53; male: } 60(80 \%) \text {; } \\
\text { etiology: DCMP } 53 \text { ( } 71 \%) \text {, ischemic } 15(20 \%) \text {, other } 7 \\
\text { (9\%). } 23 \text { LVAD-V-A ECMO (femoral vein and PA through } \\
\text { "Chimney technique") - mean age: } 51 \text {; male: } 19 \text { (83\%); } \\
\text { etiology: DCMP } 12 \text { (52\%), ischemic } 9 \text { (39\%), other } 2 \\
(9 \%)\end{array}$ \\
\hline $\begin{array}{l}\text { Scherer } \\
\text { et al. (60) }\end{array}$ & $\begin{array}{l}10 \text { LVAD-ECMO- } 6 \text { pts had ECMO before LVAD for CS } \\
\text { and after the LVAD the ECMO hasn't been removed; } 4 \\
\text { pts had ECMO after LVAD implantation; } 8 \text { femo-femoral } \\
\text { ECMO, } 2 \text { subclavian-femoral ECMO; mean age: } 53 \pm 10 \text {; } \\
\text { male: } 9 \text { ( } 90 \%) \text {; etiology: DCMP } 7 \text { ( } 70 \%) \text {, ischemic } 2 \\
\text { (20\%), myocarditis } 1 \text { (10\%); mean time support: } 8 \pm 4 \\
\text { days }\end{array}$ \\
\hline $\begin{array}{l}\text { Riebandt } \\
\text { et al. (61) }\end{array}$ & $\begin{array}{l}122 \text { isolated LVAD. } 32 \text { LVAD-ECMO-subclavian artery } \\
\text { with a side graft + femoral vein percutaneously or femo- } \\
\text { femoral ECMO percutaneously; mean age: } 52 \pm 14 \text {; male: } \\
27(84.4 \%) \text {; etiology: DCMP } 16 \text { ( } 50 \%) \text {, ischemic } 13 \\
(40.6 \%) \text {, other } 3(9.4 \%) \text {; in-hospital stay: } 37 \pm 30 \text { days }\end{array}$ \\
\hline
\end{tabular}

Isolated LVAD

vs. LVAD-RVAD

Kierman

et al. (50)

9,580 isolated LVAD. 396 LVAD-RVAD-mean age >60 y: Outcome

Isolated LVAD-survival 30-d: 75 (100\%); survival to discharge: 68 (91\%); 1-y survival: 63 (84\%); CTx: 46 (61\%); died on support: 17 (23\%). LVAD-V-A ECMO-survival 30d: 20 (87\%); survival to discharge: 19 (83\%); 1-y survival: 15 (65\%); CTx: 11 (48\%); died on support: 10 (43\%)

Weaning ECMO: 10 (100\%); mortality after weaning from ECMO: 4 (40\%) (2 sepsis, 1 mesenteric ischemia, $1 \mathrm{Gl}$ bleeding); no death RV-related; overall survival: 6 (60\%)

LVAD-ECMO-weaning ECMO: 29 (90.6\%); mortality on LVAD-ECMO: 3 (9.4\%) (1 for sepsis, 1 for MOF, 1 for ischemic stroke); mortality 30 -days: 6 (18.8\%); in-hospital mortality: 8 (25\%) [4 (12.5\%) MOF, 2 (6.3\%) sepsis, 1(4.5\%) ischemic stroke, 1 (4.5\%) hemorrhagic stroke]; 1-year survival: 24 (75\%)
Kormos

et al. (20)

Fischer et al. (62)

Deschka et al. (45)

Bhama et al. (63)

\section{$(49.7 \%)$}

386 isolated LVAD-mean age: $51.8 \pm 13.5$; male: 306 (79\%); etiology: ischemic 174 (45\%). 30 RVAD-LVADmean age: $51.0 \pm 13.3$; male: $23(77 \%)$; etiology: ischemic $15(50 \%)$

22 isolated LVAD-mean age: $61.9 \pm 8.9$; male: $19(86 \%)$; etiology: DCMP 10 (45\%), ischemic 8 (36\%), AMI 2 (9\%).

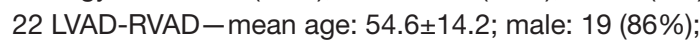
etiology: DCMP 13 (59\%), ischemic 8 (6\%), AMI 1 (5\%)
Isolated LVAD-survival 30-d: 96.1\%; LVAD-RVAD-survival 30-d: $73.5 \%$

Isolated LVAD-survival at 1-year: 78\% $\pm 3 \%$; RVAD-LVADsurvival at 1 -year: $59 \% \pm 9 \%$

Isolated LVAD-mean time to hospital discharge: 38.5 days; CTx: $10(46 \%)$; survival rate (\%): at 1 month $90.9 \pm 6.1$; at 3 months $76.5 \pm 9.2$; at 6 months $71.4 \pm 9.9$. LVAD-RVAD-mean duration RVAD support: 8.5 days; mean time to hospital discharge: 37 days; CTx: 10 (46\%); survival rate (\%): at 1 month $89.9 \pm 7.9$; at 3 months $80.5 \pm 8.8$; at 6 months $60.4 \pm 12$

Isolated LVAD-in-hospital survival: 19 (70.4\%); 1-year survival: 66.7\%. LVAD- RVAD-weaning RVAD: 23 (92\%); in-hospital death on RVAD: 2 (8\%) (1 MOF and 1 cerebral hemorrhage); in-hospital death after weaning RVAD: 6 (24\%) (5 sepsis, 1 hemorrhagic shock and MOF); in-hospital survival: 17 (68\%); follow-up at 18 months: $3 / 17$ CTx, 5/17 deceased, 9 still on LVAD; 1 -year survival: $56 \%$

Weaning RVAD: 35 (83\%); mortality $<30$ days or before discharge: 10 (24\%); mortality $>30$ days or after discharge: $13(31 \%)$

Table 2 (continued) 
Table 2 (continued)

\begin{tabular}{|c|c|c|}
\hline Study & Patients features & Outcome \\
\hline $\begin{array}{l}\text { Liedenfrost } \\
\text { et al. (64) }\end{array}$ & $\begin{array}{l}240 \text { isolated LVAD. } 15 \text { LVAD-RVAD-mean age: } 64.6 \pm 7 \text {; } \\
\text { etiology: ischemic } 12(80 \%) .12 \text { LVAD-OxyRVAD-mean } \\
\text { age: } 45.6 .6 \pm 16 \text {; etiology: ischemic } 0\end{array}$ & $\begin{array}{l}\text { LVAD-RVAD-weaning RVAD: } 10 \text { (64\%); 30-days mortality: } 7 \\
\text { (47\%). LVAD-OxyRVAD-weaning OxyRVAD: } 10 \text { (83\%); 30- } \\
\text { days mortality: } 1 \text { (8\%) }\end{array}$ \\
\hline $\begin{array}{l}\text { Ravichandran } \\
\text { et al. (65) }\end{array}$ & $\begin{array}{l}12 \text { ProtekDuo-LVAD-mean age: } 56.3 \pm 8 \text {; male: } 9(76 \%) \text {; } \\
\text { etiology: ischemic } 5(42 \%)\end{array}$ & $\begin{array}{l}\text { Weaning ProtekDuo: } 4 \text { (33\%); mortality on ProtekDuo: } 7 \\
\text { (58\%); duration ProtekDuo support: } 10.5 \pm 6.5 \text { days }\end{array}$ \\
\hline $\begin{array}{l}\text { Schmack } \\
\text { et al. (43) }\end{array}$ & $\begin{array}{l}11 \text { ProtekDuo-LVAD-mean age: } 51.6 \pm 13.1 \text {; male: } 10 \\
(90.0 \%) \text {; etiology: DCMP } 5 \text { (45.5\%), ischemic } 6(54.5 \%)\end{array}$ & $\begin{array}{l}\text { Weaning ProtekDuo: } 10 \text { (90.9\%); survival } 30-d \text { : } 8(72.7 \%) \text {; } \\
\text { mortality follow-up: } 4 \text { (36.4\%) (3 MOF, } 1 \text { cerebral } \\
\text { hemorrhage); duration ProtekDuo support: } 16.8 \pm 9.5 \text { days }\end{array}$ \\
\hline
\end{tabular}

of Impella CP for the left support and Impella RP for the right one has shown promising results $(49,75)$.

In literature, the use of $\mathrm{TH}$ for RVF is associated with a widely different mortality, with the lowest in the afterLVAD setting. Patients who didn't survived to hospital discharge were older and had biventricular failure or major bleeding complications $(7,76,77)$.

The choice of the mechanical support in such a setting is still a challenge. In the decision-making, it is important to consider the timing of RVF occurrence and the strategy of the LVAD implantation. If the RVF occurs in the operating room, valid options might be a direct RV support (RA and PA cannulation) or to consider a peripheral V-A ECMO as temporary support. An additional intra-operative approach might include a dedicated RV support with RA drainage through a femoral vein and graft-interposed PA cannulation. Instead, if a full percutaneous approach is considered, implantation of a percutaneous double-lumen ProtekDuo cannula in the PA or Impella RP through the femoral vein, are good options, particularly if the RVF occurs in the ICU or perioperatively. V-A ECMO is often the first- line of support because of the facility of implantation, the availability of the machine in most of the centers, and the lower cost compared to the percutaneous or other devices. However, as previously mentioned, the effects of reduced LVAD loading and the competitive retrograde aortic flow against the LVAD ejection, should be carefully considered.

The strategy of the LVAD (bridge-to-transplantation or destination therapy) may also influence the decision-making. In any pre-LVAD implant situation, a proper RV assessment should be applied to avoid or reduce the risk of RVF regardless the strategy of the LVAD. In any post-LVAD situations, the first approach should be always a temporary $\mathrm{RV}$ support. In case of no recovery of the RV after adequate waiting time and a bridge-to-transplantation objective, an attempt to speed up the waiting time to organ availability and transplanting the patient should be pursued. In case of a destination therapy and failing temporary RV support, it is doable to consider a long-term VAD (HeartWare, Heartmate) in right position, therefore, achieving a BiVAD support. Despite the available series, however, new studies are needed to define the best mechanical cardio-circulatory 
support for RVF, the appropriate timing of implantation, and the best candidates for each of devices.

\section{Conclusions}

RVF after LVAD is rather frequent and poses a significant challenge. Prediction is difficult and prognostic scores are variable. In case of refractory RVF, the use of temporary mechanical support may be required, providing a better survival. The percutaneous $\mathrm{V}$-A ECMO is increasingly considered and with several options for post-LVAD RVF, supplying many treatments modalities and configurations. In case of RVF, a timely initiation of support provides a better survival with results comparable to those in LVAD implantation without RVF. Despite ECMO is a valuable tool, drawbacks and complications must be considered, particularly the effects on LVAD function. Finally, the development of new approaches and cannulas, such as the ProtekDuo, may lead to a minimally invasive and full percutaneous support enhancing the decision-making and management of this population. However, more studies are warranted to prove the hemodynamic and clinical effect of such attractive approaches.

\section{Acknowledgments}

Funding: None.

\section{Footnote}

Reporting Checklist: The authors have completed the PRISMA reporting checklist. Available at http://dx.doi. org/10.21037/jtd-20-2228

Conflicts of Interest: All authors have completed the ICMJE uniform disclosure form (available at http:// dx.doi.org/10.21037/jtd-20-2228). RL reports other from Medtronic, other from LivaNova, other from Eurosets, outside the submitted work. MK serves as an unpaid editorial board member of Fournal of Thoracic Disease from Sep 2020 to Aug 2022. The other authors have no conflicts of interest to declare.

Ethical Statement: The authors are accountable for all aspects of the work in ensuring that questions related to the accuracy or integrity of any part of the work are appropriately investigated and resolved.
Open Access Statement: This is an Open Access article distributed in accordance with the Creative Commons Attribution-NonCommercial-NoDerivs 4.0 International License (CC BY-NC-ND 4.0), which permits the noncommercial replication and distribution of the article with the strict proviso that no changes or edits are made and the original work is properly cited (including links to both the formal publication through the relevant DOI and the license). See: https://creativecommons.org/licenses/by-nc-nd/4.0/.

\section{References}

1. Harjola VP, Mebazaa A, Čelutkienè J, et al. Contemporary management of acute right ventricular failure: a statement from the Heart Failure Association and the Working Group on Pulmonary Circulation and Right Ventricular Function of the European Society of Cardiology. Eur J Heart Fail 2016;18:226-41.

2. Dang NC, Topkara VK, Mercando M, et al. Right heart failure after left ventricular assist device implantation in patients with chronic congestive heart failure. J Heart Lung Transplant 2006;25:1-6.

3. Scherer M, Sirat AS, Moritz S. Extracorporeal membrane oxygenation as perioperative right ventricular support in patients with biventricular failure undergoing left ventricular assist device implantation. Eur J Cardiothorac Surg 2011;39:939-44.

4. Aissaoui N, Morshuis M, Schoenbrodt M, et al. Temporary right ventricular mechanical circulatory support for the management of right ventricular failure in critically ill patients. J Thorac Cardiovasc Surg 2013;146:186-91.

5. Konstam MA, Kiernan MS, Bernstein D, et al. Evaluation and Management of Right-Sided Heart Failure: A

Scientific Statement from the American Heart Association. Circulation 2018;137:e578-622.

6. Mulaikal TA, Bell LH, Li B, et al. Isolated Right Ventricular Mechanical Support: Outcomes and Prognosis. ASAIO J 2018;64:e20-7.

7. Kapur NK, Esposito ML, Bader Y, et al. Mechanical Circulatory Support Devices for Acute Right Ventricular Failure. Circulation 2017;136:314-26.

8. Ali HR, Kiernan MS, Choudhary G, et al. Right Ventricular Failure Post-Implantation of Left Ventricular Assist Device: Prevalence, Pathophysiology, and Predictors. ASAIO J 2020;66:610-9.

9. Cordtz J, Nilson JC, Hansen PB, et al. Right ventricular failure after implantation of a continuous-flow left 
ventricular assist device: Early hemodynamic predictors. Eur J Cardiothorac Surg 2014;45:847-53.

10. Greyson CR. Pathophysiology of right ventricular failure. Crit Care Med 2008;36:S57-65.

11. Feldman D, Pamboukian SV, Teuteberg JJ, et al. The 2013 International Society for Heart and Lung Transplantation Guidelines for mechanical circulatory support: executive summary. J Heart Lung Transplant 2013;32:157-87.

12. Krishan K, Nair A, Pinney S, et al. Liberal use of tricuspidvalve annuloplasty during left-ventricular assist device implantation. Eur J Cardiothorac Surg 2012;41:213-7.

13. Kavarana MN, Pessin-Minsley MS, Urtecho J, et al. Right ventricular dysfunction and organ failure in left ventricular assist device recipients: a continuing problem. Ann Thorac Surg 2002;73:745-50.

14. Brisco MA, Sundareswaran KS, Milano CA, et al. Incidence, risk, and consequences of atrial arrhythmias in patients with continuous-flow left ventricular assist devices. J Card Surg 2014;29:572-80.

15. Turner KR. Right Ventricular Failure After Left Ventricular Assist Device Placement-The Beginning of the End or Just Another Challenge? J Cardiothorac Vasc Anesth 2019;33:1105-21.

16. Raina A, Seetha Rammohan HR, Gertz ZM, et al. Postoperative right ventricular failure after left ventricular assist device placement is predicted by preoperative echocardiographic structural, hemodynamic and functional parameters. J Card Fail 2013;19:16-24.

17. Lampert BC, Teuteberg JJ. Right ventricular failure after left ventricular assist devices. J Heart Lung Transplant 2015;34:1123-30.

18. Ochiai Y, McCathy PM, Smedira NG, et al. Predictors of severe right ventricular failure after implantable left ventricular assist device insertion: analysis of 245 patients. Circulation 2002;106:I198-202.

19. Fitzpatrick JR 3rd, Friederick JR, Hiesinger W, et al. Early planned institution of biventricular mechanical circulatory support results in improved outcome compared with delayed conversion of a left ventricular assist device to a biventricular assist device. J Thorac Cardiovasc Surg 2009;137:971-7.

20. Kormos RL, Teuteberg JJ, Pagani FD, et al. Right ventricular failure in patients with the HeartMate II continuous-flow left ventricular assist device: incidence, risk factors, and effect on outcomes. J Thorac Cardiovasc Surg 2010;139:1316-24.

21. Potapov EV, Stepanenko A, Dandel M, et al. Tricuspid incompetence and geometry of the right ventricle as predictors of right ventricular function after implantation of a left ventricular assist device. J Heart Lung Transplant 2008;27:1275-81.

22. Morgan JA, Brewer RJ, Nemeh HW, et al. Left ventricular reverse remodeling with a continuous flow left ventricular assist device measured by left ventricular end-diastolic dimensions and severity of mitral regurgitation. ASAIO J 2012;58:574-7.

23. Tang PC, Haft JW, Romano MA, et al. Right ventricular function and residual mitral regurgitation after left ventricular assist device implantation determines the incidence of right heart failure. J Thorac Cardiovasc Surg 2020;159:897-905.e4.

24. Fukuhara S, Takeda K, Chiuzan C, et al. Concomitant mitral repair and continuous-flow left ventricular assist devices: Is it warranted? J Thorac Cardiovasc Surg 2017;154:1303-1312.e4.

25. Robertson JO, Grau-Sepulveda MV, Okada S, et al. Concomitant tricuspid valve surgery during implantation of continuous-flow left ventricular assist devices: a Society of Thoracic Surgeons database analysis. J Heart Lung Transplant 2014;33:609-17.

26. Maltais S, Topilsky Y, Tchantchaleishvili V, et al. Surgical treatment of tricuspid valve insufficiency promotes early reverse remodeling in patients with axial-flow left ventricular assist devices. J Thorac Cardiovasc Surg 2012;143:1370-6.

27. Atluri P, Goldstone AB, Fairman AS, et al. Predicting right ventricular failure in the modern, continuous flow left ventricular assist device era. Ann Thorac Surg 2013;96:857-63.

28. Fukamachi K, McCarthy PM, Smedira NG, et al. Preoperative risk factors for right ventricular failure after implantable left ventricular assist device insertion. Ann Thorac Surg 1999;68:2181-4.

29. Drakos SG, Janicki L, Horne BD, et al. Risk factors predictive of right ventricular failure after left ventricular assist device implantation. Am J Cardiol 2010;105:1030-5.

30. Alnsasra H, Asleh R, Schettle SD, et al. Diastolic Pulmonary Gradient as a Predictor of Right Ventricular Failure After Left Ventricular Assist Device Implantation. J Am Heart Assoc 2019;8:e012073.

31. MacGowan GA, Schueler S. Right heart failure after left ventricular assist device implantation: early and late. Curr Opin Cardiol 2012;27:296-300.

32. Matthews JC, Koelling TM, Pagani FD, et al. The right ventricular failure risk score a pre-operative tool for assessing the risk of right ventricular failure in left 
ventricular assist device candidates. J Am Coll Cardiol 2008;51:2163-72.

33. Loforte A, Montalto A, Musumeci F, et al. Calculation of the ALMA Risk of Right Ventricular Failure After Left Ventricular Assist Device Implantation. ASAIO J 2018;64:e140-7.

34. Lo Coco V, Lorusso R, Raffa GM, et al. Clinical complications during veno-arterial extracorporeal membrane oxygenation in post-cardiotomy and non-postcardiotomy shock: still the Achilles' heel. J Thorac Dis 2018;10:6993-7004.

35. Loforte A, Baiocchi M, Gliozzi G, et al. Percutaneous PA venting via jugular vein while on peripheral extracorporeal membrane oxygenation running: a less invasive approach to provide full biventricular unloading. Ann Cardiothorac Surg 2019;8:163-6.

36. Loforte A, Baiocchi M, Dal Checco E, et al. Percutaneous PA Venting via Jugular Vein While on Peripheral Extracorporeal Life Support. ASAIO J 2020;66:e50-4.

37. de Pommereau A, Radu C, Boukantar M, et al. Left Ventricle Unloading Through Pulmonary Artery in Patients with Venoarterial Extracorporeal Membrane Oxygenation. ASAIO J 2021;67:e49-51.

38. Lorusso R, Raffa GM, Heuts S, et al. Pulmonary artery cannulation to enhance extracorporeal membrane oxygenation management in acute cardiac failure. Interact Cardiovasc Thorac Surg 2020;30:215-22.

39. Haneya A, Philipp A, Puehler T, et al. Temporary percutaneous right ventricular support using a centrifugal pump in patients with postoperative acute refractory right ventricular failure after left ventricular assist device implantation. Eur J Cardiothorac Surg 2012;41:219-23.

40. Noly PE, Kirsch M, Quessard A, et al. Temporary right ventricular support following the left ventricle assist device implantation: A comparison of two techniques. Interact Cardiovasc Thorac Surg 2014;19:49-55.

41. Lenoir M, Quessard A, N'guyen A, et al. Simplified temporary right ventricular support after implantation of a left ventricular assist device. Heart Surg Forum 2013;16:E152-4.

42. Takayama H, Naka Y, Kodali SK, et al. A novel approach to percutaneous right ventricular mechanical support Eur J Cardiothorac Surg 2012;41:423-6.

43. Schmack B, Weymann A, Popov AV, et al. Concurrent left ventricular assist device (LVAD) implantation and percutaneous temporary RVAD support via Cardiac Assist Protek-Duo TandemHeart to preempt right heart failure. Med Sci Monit Basic Res 2016;22:53-7.
44. Bermudez CA, Lagazzi L, Crespo MM. Prolonged support using a percutaneous OxyRvad in a patient with end-stage lung disease, pulmonary hypertension, and right cardiac failure. ASAIO J 2016;62:e37-40.

45. Deschka H, Holthaus AJ, Sindermann JR, et al. Can Perioperative Right Ventricular Support Prevent Postoperative Right Heart Failure in Patients with Biventricular Dysfunction Undergoing Left Ventricular Assist Device Implantation? J Cardiothorac Vasc Anesth 2016;30:619-26.

46. Wang D, Zou X, Liu X, et al. OxyRVAD for total right heart and respiratory support. Conf Proc IEEE Eng Med Biol Soc 2006;2006:5390-1.

47. Morgan JA, O'Neil WW. Percutaneous right ventricular assist device support in a patient supported by an LVAD. ASAIO J 2016;62:e41-2.

48. Anderson MB, Goldstein J, Milano C, et al. Benefits of novel percutaneous ventricular assist device for right heart failure, the prospective RECOVER RIGHT study of the Impella RP device. J Heart Lung Transplant 2015;34:1549-60.

49. Pieri M, Pappalardo F. Impella RP in the Treatment of Right Ventricular Failure: What We Know and Where We Go. J Cardiothorac Vasc Anesth 2018;32:2339-43.

50. Kiernan MS, Grandin EW, Brinkley M Jr, et al. Early Right Ventricular Assist Device Use in Patients Undergoing Continuous-Flow Left Ventricular Assist Device Implantation: Incidence and Risk Factors from the Interagency Registry for Mechanically Assisted Circulatory Support. Circ Heart Fail 2017;10:e003863.

51. Kapur NK, Paruchuri V, Jagannathan A, et al. Mechanical circulatory support for right ventricular failure. JACC Heart Fail 2013;1:127-34.

52. Schürner A, Wilhelm MJ, Falk V, et al. Recurrent clotting of a continuous-flow right ventricular assist device: repeated thrombolysis with two different protocols. J Cardiothorac Vasc Anesth 2015;29:1614-7.

53. Krabatsch T, Potapov E, Stepanenko A, et al. Biventricular circulatory support with two miniaturized implantable assist devices. Circulation 2011;124:S179-86.

54. Griffith KE, Jenkins E, Stulak J, et al. Long-term use of the CentriMag(R) Ventricular Assist System as a right ventricular assist device: a case report. Perfusion 2012;27:65-70.

55. Coromilas EJ, Takeda K, Ando M, et al. Comparison of Percutaneous and Surgical Right Ventricular Assist Device Support After Durable Left Ventricular Assist Device Insertion. J Card Fail 2019;25:105-13.

56. John R, Lee S, Eckman P, et al. Right ventricular failure- a 
continuing problem in patients with left ventricular assist device support. J Cardiovasc Transl Res 2010;3:604-11.

57. Patlolla B, Beygui R, Haddad F. Right ventricular failure following left ventricle assist device implantation. Curr Opin Cardiol 2013;28:223-33.

58. Marquez TT, D’Cunha J, John R, et al. Mechanical support for acute right ventricular failure: evolving surgical paradigms. J Thorac Cardiovasc Surg 2009;137:e30-40.

59. Shehab S, Rao S, Macdonald P, et al. Outcome of venopulmonary arterial extracorporeal life support as temporary right ventricular support left ventricular assist implantation. J Thorac Cardiovasc Surg 2018;156:2143-52.

60. Scherer M, Moritz A, Martens S. The use of extracorporeal membrane oxygenation in patients with therapy refractory cardiogenic shock as a bridge to implantable left ventricular assist device and perioperative right heart support. J Artif Organs 2009;12:160.

61. Riebandt J, Haberl T, Wiedemann D, et al. Extracorporeal membrane oxygenation support for right ventricular failure after left ventricular assist device implantation. Eur J Cardiothorac Surg 2018;53:590-5.

62. Fischer Q, Kirsch M. Liberal Right Ventricular Assist Device Extracorporeal Membrane Oxygenation Support for Right Ventricular Failure after Implantable Left Ventricular Assist Device Placement. ASAIO J 2018;64:741-7.

63. Bhama JK, Bamsal U, Winger DG, et al. Clinical experience with temporary right ventricular mechanical circulatory support. J Thorac Cardiovasc Surg 2018;156:1885-91.

64. Leidenfrost J, Prasad S, Itoh A, et al. Right ventricular assist device with membrane oxygenator support for right ventricular failure following implantable left ventricular assist device placement. Eur J Cardiothorac Surg 2016;49:73-7.

65. Ravichandran AK, Baran DA, Stelling K, et al. Outcomes with the Tandem ProtekDuo Dual-Lumen Percutaneous Right Ventricular Assist Device. ASAIO J 2018;64:570-2.

66. Soliman O, Akin S, Muslem R, et al. Derivation and Validation of a Novel Right-Sided Heart Failure Model After Implantation of Continuous Flow Left Ventricular Assist Devices: The EUROMACS (European Registry for Patients with Mechanical Circulatory Support) Right-Sided Heart Failure Risk Score. Circulation 2018;137:891-906.

67. Welp H, Sindermann JR, Deschka H, et al. Pulmonary Bleeding During Right Ventricular Support After Left Ventricular Assist Device Implantation. J Cardiothorac Vasc Anesth 2016;30:627-31.
68. Dalen M, Sartip U, Lund LH, et al. Peripheral Extracorporeal Membrane Oxygenation as ShortTerm Right Ventricular Support After HeartWare Left Ventricular Assist Device Implantation. ASAIO J 2013;59:523-5.

69. Shehab S, Hayward CS. Choosing Between Left Ventricular Assist Devices and Biventricular Assist Devices. Card Fail Rev 2019;5:19-23.

70. Patel NJ, Verma DR, Gopalan R, et al. Percutaneous Biventricular Mechanical Circulatory Support with Impella CP and Protek Duo Plus TandemHeart. J Invasive Cardiol 2019;31:E46.

71. Xu T, Trimlett S, Davies S, et al. Use of ProtekDuo in patients with acute right ventricular failure. Conference: 8th EuroELSO Congress; 10-13.04.2019 At Barcellona, Spain. Volume: Perfusion Supplement, Vol 34(15) 139140.

72. Kazui T, Tran PL, Echeverria A, et al. Minimally invasive approach for percutaneous CentriMag right ventricular assist device support using a single PROTEKDuo Cannula. J Cardiothorac Surg 2016;11:123.

73. Anderson M, Morris DL, Tang D, et al. Outcomes of patients with right ventricular failure requiring short-term hemodynamic support with the Impella RP device. J Heart Lung Transplant 2018;37:1448-58.

74. Cheung AW, White CW, Davis MK, et al. Short-term mechanical circulatory support for recovery from acute right ventricular failure: clinical outcomes. J Heart Lung Transplant 2014;33:794-9.

75. Pappalardo F, Scandroglio AM, Latib A. Full percutaneous biventricular support with two Impella pumps: The BIPella Approach ESC Heart Failure 2018. ESC Heart Fail 2018;5:368-71.

76. Kapur NK, Paruchuri V, Korabathina R, et al. Effects of a percutaneous mechanical circulatory support device for medically refractory right ventricular failure. J Heart Lung Transplant 2011;30:1360-7.

77. Loor G, Khani-Hanjani A, Gonzalez-Stawinski GV. Use of RotaFlow DMAQUET for temporary right ventricular support during implantation of HeartMate II left ventricular assist device. ASAIO J 2012;58D3:275-7.

Cite this article as: Lo Coco V, De Piero ME, Massimi G, Chiarini G, Raffa GM, Kowalewski M, Maessen J, Lorusso R. Right ventricular failure after left ventricular assist device implantation: a review of the literature. J Thorac Dis 2021;13(2):1256-1269. doi: 10.21037/jtd-20-2228 